chất trong khi phim Salbutamol sulfat giải phóng nhanh giải phóng được khoảng 83,2\% dược chất. Do đó, phim đã thể hiện rõ mô hình đối với dạng bào chế cần giải phóng nhanh

Bảng 7. Tỷ lệ (\%) Salbutamol sulfat giải phóng từ viên đôi chiêu và phim Salbutamol sulfat GPN $(n=6 ; \bar{X} \pm S D)$

\begin{tabular}{|c|c|c|c|c|c|c|}
\hline \multirow{2}{*}{ CT } & \multicolumn{5}{|c|}{ Tỷ lệ (\%) Salbutamol giải phóng theo thời gian (phút) } \\
\cline { 2 - 7 } & $\mathbf{1}$ & $\mathbf{3}$ & $\mathbf{5}$ & $\mathbf{1 0}$ & $\mathbf{2 0}$ & $\mathbf{3 0}$ \\
\hline Viên đối chiếu & $13,4 \pm 0,8$ & $27,8 \pm 1,2$ & $45,3 \pm 2,1$ & $61,4 \pm 2,9$ & $85,6 \pm 3,5$ & $95,8 \pm 4,2$ \\
\hline CT tối ưu & $55,9 \pm 2,9$ & $72,5 \pm 3,3$ & $83,2 \pm 4,4$ & $95,8 \pm 4,7$ & $98,4 \pm 4,8$ & $99,3 \pm 4,1$ \\
\hline Inform & 56,9 & & 85,0 & & & 99,8 \\
\hline
\end{tabular}

\section{KẾT LUẬN}

- Đã tối ưu hóa công thức phim salbutamol sulfat $4 \mathrm{mg}$ giải phóng nhanh bằng đổ khuôn và bốc hơi dung môi ở quy mô phòng thí nghiệm. Với thành phần công thức tối ưu gồm có: Salbutamol sulfat 666,67mg; PVA 2,01\%; Glucose 1\%; PG 0,0201\%; Natri lauryl sulfat 0,85\%; Nước cất 20ml; Ethanol 70\% vừa đủ 100 $\mathrm{ml}$; đổ khuôn $15 \mathrm{ml}$ vào đĩa petri đường kính $5 \mathrm{~cm}$; đường kính kính phim $10 \mathrm{~mm}$.

- Trong thử nghiệm hòa tan invitro cho thây dược chất giải phóng từ phim Salbutamol sulfat nhanh hơn so với viên đối chiếu (83,2\% so với 45,3\% sau 5 phút).

TÀI LIỆ THAM KHẢO

1. Verma R., Sanjay G. (2001), Current status of drug delivery technologies and future directions, Pharm. Technol., 25, pp. 1-14.

2. Dipika p., Upendra P., et al. (2012), Orally fast dissolving films as dominant dosage form for quick release, IJPRBS, 1(3), pp. 27- 41.

3. Nhâm Phương Thảo, Nguyễn Văn Bạch, Nguyễn Minh Chính và CS (2015), Ảnh hưởng của một số tá dược đến độ giải phóng của salbutamol từ phim giải phóng nhanh đặt tại khoang miệng, Tạp chí Y Dược học quân sự, Vol 40 (06), tr. 11-16.

4. Apoorva M., Neha C., Geeta A. (2011), Formulation and characterization of fast dissolving buccal films: A review, Der. Phar. Lettre, 3(1), pp. 152-165.

5. Mishra R., Amin A. (2005), Quick API Delivery, Pharmaceutical Technology Europe, pp. 1-5.

6. Prasanthi N. L., Sowmya K. C. et al. (2011), Design and development of sublingual fast dissolving films for an antiasthmatic drug, Der Pharmacia Lettre, 3(1), pp. 382-395.

\title{
THẨM ĐỊNH PHƯƠNG PHÁP ĐỊNH LƯợNG SALBUTAMOL SULFAT TRONG PHIM SALBUTAMOL SULFAT GIẢI PHÓNG NHANH BẰNG SẮC KÝ LỎNG HIỆU NĂNG CAO
}

\author{
Trịnh Nam Trung*, Nguyễn Văn Bạch*, Nguyễn Văn Minh*
}

\section{TÓM TẮT}

Mục tiêu: Thẩm định phương pháp định lượng salbutamol sulfat trong phim salbutamol sulfat giải phóng nhanh bằng sắc ký lỏng hiệu năng cao (HPLC) nhằm góp phần tiêu chuẩn hóa chất lượng sản phẩm. Đối tượng và phương pháp: Tiến hành định lượng salbutamol sulfat bằng phương pháp HPLC với cột sắc

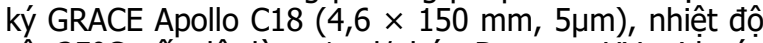
côt $25^{\circ} \mathrm{C}$, tốc đô dòng $1 \mathrm{ml} /$ phút, Detector UV tai bước sóng $276 \mathrm{~nm}$, thể tích tiêm $20 \mu \mathrm{l}$, pha động gồm dung dịch natri dihydrophosphat $\mathrm{pH} 3,1$ và methanol (85:15). Kết quả: Phương pháp đảm bảo tính thích hợp, tính đặc hiệu, khoảng tuyến tính, độ lặp lại và độ đúng theo qui định của ICH. Kết luận: Phương pháp

*Học viện Quân y

Chịu trách nhiệm chính: Trịnh Nam Trung

Email: tntqy114@gmail.com

Ngày nhận bài: $1 / 9 / 2021$

Ngày phản biên khoa học: 30/9/2021

Ngày duyệt bài: 19/10/2021 định lượng đảm bảo các yêu cầu và có thể sử dụng để định lượng salbutamol sulfat trong phim salbutamol sulfat giải phóng nhanh.

Tư khóa: Salbutamol sulfat, phim giải phóng nhanh, ICH.

\section{SUMMARY}

VALIDATION ASSAY METHOD FOR SALBUTAMOL SULFATE IN FAST DISSOLVING FILM BY HIGH PERFORMANCE LIQUID CHROMATOGRAPHY

Objective: To validate a method for the quantification of salbutamol sulfate in fast dissolving film by high performance liquid chromatography (HPLC) in order to contribute to product quality standardization. Subjects and methods: Quantitative salbutamol sulfate by HPLC method with GRACE Apollo C18 column $(4.6 \times 150 \mathrm{~mm}, 5 \mu \mathrm{m})$, column temperature $25^{\circ} \mathrm{C}$, flow rate $1 \mathrm{ml} / \mathrm{min}$, detector UV at $276 \mathrm{~nm}$, injection volume $20 \mu \mathrm{l}$, mobile phase consisting of sodium dihydrophosphate solution pH 3.1 and methanol (85:15). Results: The method ensured suitability, specificity, linearity, repeatability, 
and precision as specified by $\mathrm{ICH}$. Conclusion: The quantitative method meets the requirements and can be used for the quantification of salbutamol sulfate in the fast-dissolving film of salbutamol sulfate.

Keywords: Salbutamol sulfate, fast dissolving film, ICH.

\section{I. ĐẶT VẤN ĐỀ}

Salbutamol sulfat là chất chủ vận thụ thể adrenergic $\beta 2$, được sử dụng lần đầu tiên vào năm 1968, cho đển nay vẫn là lựa chọn hàng đầu trong điêu trị hen phế quản cẩp và mạn tính [1], [2]. Khi sử dụng thuốc đường uống sẽ gặp khó khăn đối với các bệnh nhân như: Người già, trẻ em và những người gặp khó khăn khi nuốt hoặc nhai. Vì vậy, hệ thống giải phóng nhanh đã ra đời vào thập kỷ 1970 đã khắc phục được nhược điểm này. Phim giải phóng nhanh là một trong những hệ thống giải phóng nhanh được sử dụng trong trường hợp bệnh nhân gặp khó khăn khi nuốt hoặc buồn nôn khi điều trị. Khi sử dụng dược chất sẽ được hấp thu qua niêm mạc nhờ hệ thống tĩnh mạch dầy đặc tại niêm mạc miệng và còn được gọi là phim hòa tan tại khoang miêng [3], [4]. Việc kiểm tra chất lượng thuốc nhẳm đảm bảo hiệu quả điều trị và an toàn cho người sử dụng là một tiêu chí rất quan trọng. Vì vậy, nghiên cứu này được thực hiện nhẳm góp phần cung cấp các dữ liệu về phương pháp định lượng salbutamol sulfat trong phim salbutamol sulfat giải phóng nhanh và áp dụng để đánh giá chất lượng một số chế phẩm đang lưu hành.

\section{II. ĐỐI TƯợNG VÀ PHƯƠNG PHÁP NGHIÊN CỨU \\ 2.1. Nguyên vật liệu \\ *Nguyên vật liệu \\ - Salbutamol sulfat chuẩn: Đạt chuẩn phòng} thí nghiệm (SKS: 0201042; hàm lượng: 99,50\%; độ ẩm: 0,06\%) do Viện kiểm nghiệm thuốc TW cung cấp.

- Methanol, natri dihydrophosphat: Đạt tiêu chuẩn P.A (Merck Đức).

\subsection{Thiết bi nghiên cứu}

- Máy sắc ký lỏng hiệu năng cao (HPLC) Shimadzu 10A - VP (Nhật).

- Cân phân tích Mettler toledo có độ chính xác 0,1mg (Thụy Sỹ).

- Màng lọc nilon Sartorius Minisart kích thước màng $0,45 \mu \mathrm{m}$ (Đức).

- Hể thống phễu thuỷ tinh Sartotius (Đức).

- Các dụng cụ khác đạt tiêu chuẩn phân tích.

\subsection{Phương pháp nghiên cứu}

*Điêu kiện săc ký

- Pha tĩnh: Cột sắc ký GRACE Apollo C18 (4,6

$\times 150 \mathrm{~mm}, 5 \mu \mathrm{m})$.

- Nhiệt độ cột: $25^{\circ} \mathrm{C}$.
- Tốc độ dòng: 1 ml/phút.

- Detector: UV tại bước sóng 276 nm.

- Thể tích tiêm: $20 \mu \mathrm{l}$.

- Pha động: Dung dịch natri dihydrophosphat $\mathrm{pH} 3$, 1: methanol $(85: 15)$.

\section{* Phương pháp xử lý mẫu}

- Dung dịch chuẩn: Dung dịch chứa salbutamol sulfat chuẩn trong pha động có nồng độ $96 \mu \mathrm{g} / \mathrm{ml}$.

- Dung dịch thử: Nghiền mịn 20 phim, cân chính xác lượng bột tương ứng với khoảng $4,8 \mathrm{mg}$ salbutamol sulfat vào bình định mức 50 $\mathrm{ml}$, thêm khoảng $40 \mathrm{ml}$ pha động, lắc để hòa tan và thêm pha động vừa đủ đến vạch, lắc đều. Lọc qua màng lọc $0,45 \mu \mathrm{m}$.

\section{*Thẩm định phương pháp}

Quy trình thẩm định phương pháp định lượng tiến hành theo hướng dẫn của ICH [5]:

- Tính thích hợ hệ thống: Hòa tan salbutamol sulfat chuẩn trong pha động để được dung dịch có nồng độ $96 \mu \mathrm{g} / \mathrm{ml}$. Tiến hành sẳc ký 6 lần cùng một dung dịch chuẩn.

- Tính đặc hiệu: Chuẩn bị dung dịch thử bằng cách cân chính xác một lượng bột phim salbutamol sulfat giải phóng nhanh tương ứng khoảng $4,8 \mathrm{mg}$ salbutamol sulfat, thêm $40 \mathrm{ml}$ pha động, lắc siêu âm 10 phút để hòa tan và thêm pha động đến vạch vừa đủ $50 \mathrm{ml}$. Tiến hành phân tích dung dịch chuẩn, dung dịch thử và mẫu trắng (chưa tá dược) theo phương pháp đã xây dựng.

- Khoảng tuyến tính: Hòa tan $10,0 \mathrm{mg}$ salbutamol sulfat chuẩn vừa đủ trong $10 \mathrm{ml}$ pha động, thu được dung dịch chuẩn gốc có nồng độ $1000 \mu \mathrm{g} / \mathrm{ml}$. Từ dung dịch chuẩn gốc pha loãng bằng pha động thành dãy dung dịch chuẩn có nồng độ 57,$6 ; 76,8 ; 96,0 ; 115,2$ và $134,4 \mu \mathrm{g} / \mathrm{ml}$. Phân tích các dung dịch chuẩn theo phương pháp đã xây dựng. Sử dụng diện tích píc salbutamol sulfat làm tín hiệu đáp ứng để lập đường chuẩn.

- Độ lặp lại: Tiến hành phân tích 6 dung dịch thử được chuẩn bị song song theo phương pháp đã xây dựng. Tính độ lệch chuẩn tương đối (RSD) của kêt quả phân tích.

- Độ đúng: Các dung dịch thử thêm chuẩn được chuẩn bị bằng cách cân chính xác một lượing khoảng $2,1 \mathrm{mg}$ salbutamol sulfat chuẩn vào mẫu thử (6 mẫu), sau đó xử lý mẫu như đối với mẫu thử ở trên. Tiến hành sắc ký 6 dung dịch thử thêm chuẩn, dung dịch chuẩn và dung dịch thử. Từ kết quả phân tích, tính độ đúng của phương pháp.

\section{KẾT QUẢ NGHIÊN CỨU VÀ BÀN LUÂ̂N 3.1. Kết quả thẩm định tính tương thích}


của hệ thống. Bằng cách tiêm lặp lại 6 lân dung dịch chuẩn có nồng độ $96 \mu \mathrm{g} / \mathrm{ml}$ và ghi lại giá trị về thời gian lưu $\left(T_{R}\right)$, diện tích pic, hệ số bất đối xứng, số đĩa lý thuyết. Kết quả được trình bày ở bảng 1 .

Bảng 1. Kết quả khảo sát độ tương thích của hệ thống sắc ký

\begin{tabular}{|c|c|c|c|}
\hline STT & $\begin{array}{c}\text { Thời } \\
\text { gian lưu } \\
\text { (phút) }\end{array}$ & $\begin{array}{c}\text { Diện } \\
\text { tích pic } \\
\text { (mAU.s) }\end{array}$ & $\begin{array}{c}\text { Hê̂ số } \\
\text { bất đối } \\
\text { xú́ng (F) }\end{array}$ \\
\hline 1 & 6,806 & 744,2 & 1,016 \\
\hline 2 & 6,849 & 746,8 & 1,029 \\
\hline 3 & 6,905 & 744,9 & 1,022 \\
\hline 4 & 6,788 & 745,2 & 1,052 \\
\hline 5 & 6,959 & 745,8 & 1,045 \\
\hline 6 & 6,912 & 746,2 & 1,024 \\
\hline TB & 6,870 & 745,5 & 1,031 \\
\hline RSD (\%) & 0,9 & 0,1 & 0,012 \\
\hline
\end{tabular}

Kết quả khảo sát cho thấy độ thích hợp của hệ thống cho RSD (\%) của thời gian lưu bằng $0,9 \%$ và diện tích pic bằng $0,1 \%$ đều nằm trong khoảng cho phép (nhỏ hơn $2 \%$ ). Điều này chứng tỏ hệ thống phù hợp và đảm bảo độ ổn định cho phép phân tích định lượng salbutamol sulfat.

\subsection{Kết quả thẩm định độ đặc hiệu của phương pháp}

Mục đích nhằm chứng minh sự có mặt của tá dược và dung môi pha động không ảnh hưởng đến phương pháp phân tích. Khảo sát trên mẫu tự tạo gồm: Mẫu thử (salbutamol sulfat) và mẫu trắng (hỗn hợp tá dược có thành phần giống như công thức phim). Kết quả phân tích sắc ký đồ được ghi ở hình 1.

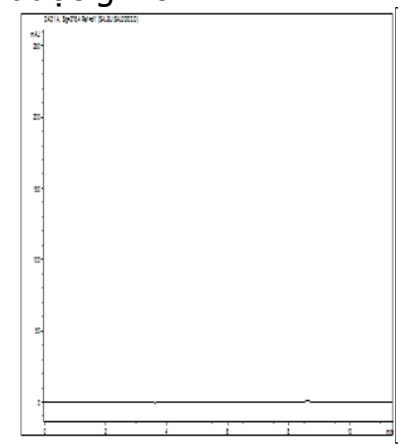

(a)



(b)
Hình 1. Sắc ký đồ của mẫu trắng (a) và của mẫu thư (b)

Kết quả ở hình 1 cho thấy: Trong mẫu thử, pic của salbutamol sulfat xuất hiện sau khoảng 6,87 phút (b). Tại vị trí pic của salbutamol sulfat, không thấy xuất hiện pic lạ trên sắc ký đồ của mẫu trắng (a). Điều đó chứng tỏ: tá dược và dung môi pha động không làm ảnh hưởng đến kết quả định lượng salbutamol sulfat bằng phương pháp HPLC.

3.3. Kết quả thẩm định độ tuyến tính của phương pháp. Khảo sát sự phụ thuộc tuyến tính giữa diện tích pic và nồng độ salbutamol sulfat bằng cách pha một dãy dung dịch salbutamol sulfat chuẩn có nồng độ từ 60$140 \mu \mathrm{g} / \mathrm{ml}$. Tiến hành sắc ký, kết quả được trình bày ở bảng 2 và hình 2 .

Bảng 2. Mối liên quan giữa nồng độ salbutamol sulfat và diện tích pic

\begin{tabular}{|c|c|c|c|c|c|}
\hline Nồng độ $(\mu \mathrm{g} / \mathrm{ml})$ & 57,6 & 76,8 & 96,0 & 115,2 & 134,4 \\
\hline Diện tích pic $(\mathrm{mAU} . \mathrm{s})$ & 663,6 & 709,0 & 746,6 & 788,1 & 829,6 \\
\hline Kết quả & \multicolumn{5}{c|}{$\begin{array}{c}\text { Phương trình hồi quy: } \mathrm{Y}=2,1411 \mathrm{X}+541,83 \\
\text { Hệ số tương quan tuyến tính: } \mathrm{R}^{2}=0,9994\end{array}$} \\
\hline
\end{tabular}

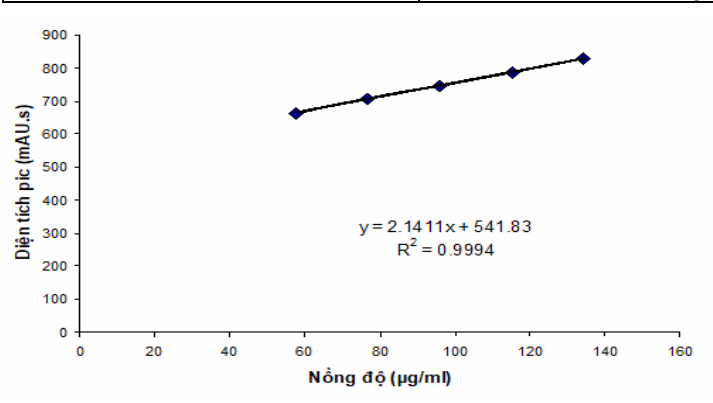

Hình 2. Đồ thị biểu diễn sự phụ thuộc tuyến tính của diện tích pic và nồng độ salbutamol sulfat

Kết quả ở bảng 2 và hình 2 cho thây: Trong khoảng nồng độ từ $57,6-134,4 \mu \mathrm{g} / \mathrm{ml}$ thu được đường chuẩn có hệ số $\mathrm{R}^{2}=0,9991$ (nằm trong 0,99-1). Điều này khẳng định có sự phụ thuộc tuyến tính chặt chẽ giữa diện tích píc với nồng độ salbutamol sulfat trong khoảng nồng độ từ $57,6-134,4 \mu \mathrm{g} / \mathrm{ml}$. Vì vậy, có thể sử dụng phương pháp đã xây dựng để định lượng salbutamol sulfat bằng cách so sánh diện tích píc của dung dịch thử với dung dịch chuẩn có nồng độ khoảng $96 \mu \mathrm{g} / \mathrm{ml}$ nằm trong khoảng tuyến tính định lượng salbutamol sulfat trong chế phẩm.

3.4. Kết quả thẩm định độ lặp lại của phương pháp. Tiến hành khảo sát độ lặp lại của phương pháp đối với mẫu phim salbutamol sulfat giải phóng nhanh. Độ lặp lại được đánh giá dựa trên độ lặp lại của 6 thí nghiệm riêng biệt. Kết quả được trình bày ở bảng 3 .

Bảng 3. Kết quả khảo sát độ lặp lại của phương pháp

\begin{tabular}{|c|c|c|}
$\begin{array}{c}\text { Khối lượng } \\
\text { cân (g) }\end{array}$ & $\begin{array}{c}\text { Diện tích pic } \\
\text { (mAU.s) }\end{array}$ & $\begin{array}{c}\text { Hàm lượng } \\
(\%)\end{array}$ \\
\hline
\end{tabular}




\begin{tabular}{|c|c|c|}
\hline 0,0286 & 636,8 & 102,8 \\
\hline 0,0278 & 613,5 & 98,8 \\
\hline 0,0280 & 618,1 & 99,6 \\
\hline 0,0271 & 631,3 & 101,6 \\
\hline 0,0278 & 615,0 & 99,1 \\
\hline 0,0288 & 630,6 & 101,5 \\
\hline \multicolumn{2}{|c|}{ X $=100,6 \% ; R S D=1,6 \%$} \\
\hline
\end{tabular}

Kết quả ở bảng 3 cho thấy: Với chương trình sắc ký đã chọn, phương pháp định lượng salbutamol sulfat có độ lặp lại cao, độ lệch chuẩn tương đối là 1,6\% (<2\%), đạt yêu cầu theo tiêu chuẩn quy định.

3.5. Kết quả thẩm định độ đúng của phương pháp. Tiến hành xác định độ đúng bằng phương pháp thêm chuẩn. Thêm một lượng salbutamol sulfat chuẩn khoảng 2,1mg vào mẫu thử sao cho nồng độ vẫn nằm trong khoảng tuyến tính đã khảo sát. Kết quả được trình bày ở bảng 4.

Bảng 4. Kết quả khảo sát độ đúng của phương pháp

\begin{tabular}{|c|c|c|c|}
$\begin{array}{c}\text { Lượng } \\
\text { chuẩn thêm } \\
\text { vào (mg) }\end{array}$ & $\begin{array}{c}\text { Diện tích pic } \\
\text { của mấu thử + } \\
\text { chuẩn(mAU.s) }\end{array}$ & $\begin{array}{c}\text { Lượng } \\
\text { chuấn tìm } \\
\text { thấy (mg) }\end{array}$ & $\begin{array}{c}\text { \% } \\
\text { tìm } \\
\text { thấy }\end{array}$ \\
\hline 2,1 & 955,2 & 2,15 & 102,4 \\
\hline 2,1 & 945,4 & 2,09 & 99,5 \\
\hline 2,1 & 943,7 & 2,08 & 99,1 \\
\hline 2,1 & 942,8 & 2,07 & 98,6 \\
\hline 2,1 & 950,8 & 2,12 & 100,1 \\
\hline 2,1 & 952,3 & 2,13 & 101,4 \\
\hline \multicolumn{2}{|c|}{$X=100,2 \%$ RSD $=1,4 \%$} \\
\hline
\end{tabular}

Kết quả ở bảng 4 cho thấy: Phương pháp có tỷ lệ thu hôi ở 6 mẫu khác nhau đạt từ 99,1 102,4\% đêu nằm trong khoảng 98 - 102\% so với lượng chuẩn thêm vào; RSD thu được bằng
$1,2 \%<2 \%$. Chứng tỏ phương pháp đã xây dựng có độ đúng cao.

*Tóm lại: Chương trình HPLC đã xây dựng có khoảng tuyến tính thích hợp, độ đúng, độ lặp lại cao và cho kết quả đáng tin cậy. Có thể áp dụng phương pháp HPLC với các điều kiện trên để xác định hàm lượng salbutamol sulfat trong phim salbutamol sulfat giải phóng nhanh.

\section{KẾT LUẬN}

- Đã lựa chọn điêuu kiện định lượng bằng sắc ký lỏng hiệu năng cao như sau: salbutamol sulfat chuẩn hoằc bột phim được hòa tan trong pha động để được nông độ khoảng $96 \mu \mathrm{g} / \mathrm{ml}$, tiến hành sắc ký và so sánh diện tích píc thu được. Điều kiện sắc ký: Cột sắc ký GRACE Apollo C18 $(4,6 \times 150 \mathrm{~mm}, 5 \mu \mathrm{m})$, nhiệt độ cột $25^{\circ} \mathrm{C}$, tốc độ dòng $1 \mathrm{ml} /$ phút, Detector UV tại bước sóng 276 nm, thể tích tiêm $20 \mu \mathrm{l}$, pha động gồm dung dịch natri dihydrophosphat $\mathrm{pH} 3,1$ và methanol (85:15).

- Phương pháp cũng được thẩm định đây đủ các chỉ tiêu theo hướng dẩn của $\mathrm{ICH}$ về thẩm định phương pháp phân tích.

\section{TÀI LIÊU THAM KHẢO}

1. Bộ Y tế (2002), Dược thư quốc gia Việt nam, NXB Y hoc, tr. 862-865.

2. Bộ Y tế (2009), Hóa dược 2, NXB Y học, tr. 451-452.

3. Dinge A., Nagarsenker M. (2008), Formulation and evaluation of fast dissolving films for delivery of triclosan to the oral cavity, AAPS Pharm. Sci. Tech., 9(2), pp. 349-356.

4. Verma R., Sanjay G. (2001), Current status of drug delivery technologies and future directions, Pharm. Technol., 25, pp. 1-14.

5. International Conference on Harmonisation (2005), ICH Q2 (R1) Validation of analytical procedures: Text and methodology.

\section{TỐI ƯU CHO SỰ PHÁT TRIỂN CỦA PHÔI TRONG NỒNG Độ OXY 20\%: MÔI TRƯỜNG ĐƠN BƯỚC HAY ĐA BƯỚC?}

\section{TÓM TẮT}

\author{
${ }^{1}$ Bệnh viện $16 A$ Hà Đông \\ ${ }^{2} \oplus H Q G$ Hà Nôi; \\ ${ }^{3}$ Học viện Quân y \\ Chiu trách nhiêm chính: Nguyễn Linh Chi \\ Email: linhchi148@gmail.com \\ Ngày nhận bài: 29/8/2021 \\ Ngày phản biên khoa học: 29/9/2021 \\ Ngày duyệt bài: 15/10/2021
}

\section{Nguyễn Linh Chi ${ }^{1,2}$, Ngô Thị Tường Châu ${ }^{2}$ Nguyễn Đình Tảo ${ }^{1}$, Nguyễn Ngọc Diệp ${ }^{3}$}

Do nhiều nguyên nhân, tình trang vô sinh nam nữ đang ngày môtt tăng cao. Điều này thúc đẩy các nhà khoa học tìm kiếm loại môi trường tối ưu, đây mạnh chất lượng nuôi cấy và nâng tỷ lệ thành công cho các cặp vợ chồng mong con. Trong công trình nghiên cứu này chúng tối đánh giá sư phát triển 1713 phôi từ giai đoạn hợp tử tới phôi nang trong thời gian 10/20192/2021. Nang trưởng thành được nuôi cấy trong môi trường đơn bước Global total ${ }^{\circledR}$ từ ngày 1 đến ngày 5 , hoăc nuôi cấy trong môi trường đa bước G1-PLUSTM đến ngày 3 , và thay sang môi trường G2-PLUSTM từ ngày 3 đến ngày $5 /$ ngày 6 . Kết quả cho thấy, môi 